\title{
Light and electron microscopic study on the effect of antischizophrenic drugs on the structure of seminiferous tubules of adult male albino rats
}

\author{
Hala M. Soliman' ${ }^{1}$ Heba M. Wagih ${ }^{2}$, Ghalia M. Attia ${ }^{3}$, Sami A. Algaidi ${ }^{4}$ \\ ${ }^{1}$ Department of Anatomy, Faculty of Medicine, Taibah University, Al Madina Al Monawarrah, \\ Kingdom of Saudi Arabia; Department of Histology and Cell Biology, Faculty of Medicine, \\ Zagazig University, Zagazig, Egypt \\ ${ }^{2}$ Department of Medical Laboratory Technology, Faculty of Applied Medical Science, Taibah \\ University, Al Madian Al Monawarrah, Kingdom of Saudi Arabia; Department of Pathology, \\ Faculty of Medicine, Suez Canal University, Ismailia, Egypt \\ ${ }^{3}$ Department of Anatomy, Faculty of Medicine, Taibah University, Al Madina Al Monawarrah, \\ Kingdom of Saudi Arabia; Department of Histology and Cell Biology, Faculty of Medicine, \\ Mansoura University, Al Mansoura, Egypt \\ ${ }^{4}$ Department of Anatomy, Faculty of Medicine, Taibah University, Al Madina Al Monawarrah, \\ Kingdom of Saudi Arabia
}

\begin{abstract}
Introduction. Sexual dysfunction and infertility are symptoms which have been rarely studied in patients treated with antischizophrenic drugs, aripiprazole and olanzapine, for long period. This work aimed to investigate the effects of aripiprazole and olanzapine on the structure of seminiferous tubules of rats at both light microscopic and ultrastructural levels.

Material and methods. Sixty adult male rats were divided into 3 groups $(\mathrm{n}=20)$ : control group (Group I) and two experimental ones (II and III). Rats in Group II received $2 \mathrm{mg} / \mathrm{kg}$ /day aripiprazole while rats in Group III received $0.5 \mathrm{mg} / \mathrm{kg} /$ day olanzapine for 14 weeks. Thereafter, testis were removed and processed for both light and electron microscopic study. Qualitative morphological analyses and histomorphometric measurements of seminiferous tubules were performed.

Results. Rats in Group II showed reduction of testicular weight, seminiferous tubules' diameter, epithelial height, spermatogenic count, spermatogenic index and spermatogenic score whereas Sertoli cells count was increased. Olanzapine-treated rats also showed epithelial desquamation, separation and apoptotic changes of germ cells. Sertoli cells showed vacuolization, dilatation of smooth endoplasmic reticulum and accumulation of lipid droplets. Abnormality in the shape and structure of late spermatids and presence of giant cells were also demonstrated. Aripiprazole induced less adverse histological changes in rat testis than olanzapine.

Conclusions. Olanzapine followed by aripiprazole had adverse histological effects on the structure of the seminiferous tubules, which may affect spermatogenesis. (Folia Histochemica et Cytobiologica 2014, Vol. 52, No. 4, $335-349)$
\end{abstract}

Key words: olanzapine; aripiprazole; rat; testis; ultrastructure; morphometry; spermatogenesis

\footnotetext{
Correspondence address: Prof. Hala M. Soliman

Department of Anatomy

Faculty of Medicine, Taibah University

Al Madina Al Monawarrah, Kingdom of Saudi Arabia

tel.: 00966592042135; fax: 00966048484316

e-mail: halasoliman2012@hotmail.com
} 


\section{Introduction}

Schizophrenia is a chronic and severe debilitating mental illness that affects $1 \%$ of the population [1]. Many studies have shown a relationship between schizophrenia and hyperactivity of the dopaminergic system [2]. Therefore, drugs that inhibit dopamine receptors have been used in the treatment of schizophrenia.

Several studies showed that drugs acting on the central nervous system (CNS) have adverse effects on male reproductive functions [3]. It was proved that antischizophrenic drugs resulted in hyperprolactinemia. Prolactin is secreted by the anterior pituitary and is under inhibitory control of dopamine released from the tuberoinfundibular neurons. Thus, increases in prolactin are due to antipsychotic impact on tuberoinfundibular tract, one of four dopamine-related tracts. These drugs act by blocking dopamine receptors and increasing the conversion of androgens to estrogens leading to the elevation of plasma estrogen levels resulting in impotence, loss of libido and hypospermatogenesis [4].

Olanzapine is an atypical second generation antipsychotic drug that has been increasingly used in acute treatment of schizophrenia, bipolar disorder and psychoses. Olanzapine acts on the dopaminergic receptor by specifically blocking 5-hydroxytryptamine (5-HT) and dopamine 2 receptors (D2). Some studies showed that hyperprolactinemia is rare with some atypical antipsychotics including olanzapine, and for this reason the term 'prolactin-sparing' has been used [5]. On the other hand, other authors found that olanzapine is associated with hyperprolactinemia [6].

Aripiprazole belongs to third generation atypical antipsychotics used in the treatment of schizophrenia. Similarly to other antipsychotic drugs, aripiprazole acts at dopamine D2 receptors in the limbic system, however, rather as a partial agonist than an antagonist [7]. A partial agonist will displace dopamine at its receptors, as would an antagonist, but instead of completely blocking the receptor and preventing receptor's activity it behaves like a weaker version of dopamine itself. This does not result in any weaker action as an antipsychotic, but should lead to improved tolerability. Moreover, some authors suggested that aripiprazole may reverse hyperprolactinemia caused by other antipsychotics [8]. However, the extent to which these effects differ from other atypical antipsychotics is debated [9].

Considering that both aripiprazole and olanzapine act on the dopaminergic receptor and this receptor has been detected in germ cells [10] and only few studies concerned their adverse histological effects on the structure of seminiferous tubules, the present study was designed to detect changes induced by these antischizophrenic drugs using both light and electron microscopy.

\section{Material and methods}

Animals and design of experiment. Sixty adult male healthy Wister albino rats (4-month old and 150-160 g weight), purchased from King Abd Al Aziz University Animal House, Jeddah, KSA, were used throughout the study. Rats were adapted for 10 days to controlled conditions of temperature, illumination and allowed free access to commercial rat chow (purchased from EL Nasr Pharmaceutical Chem. Co., New Maadi, Cairo, Egypt) and water ad libitum. All experiments were carried out in accordance with protocol approved by the local experimental ethical committee at Dean of Scientific Research, Taibah University, Al Medina Al Monawarrah, KSA.

Rats were divided into 3 groups (20 animals in each group). Group I served as control untreated rats. They were maintained on the previous conditions for 14 weeks. Group II contained rats that received aripiprazole (Bristol Myer Squib, Park Avenue, NY, USA) at a dose of $2 \mathrm{mg} / \mathrm{kg} /$ day, according to drug calculation formula [11]. Each tablet containing $20 \mathrm{mg}$ of drug was dissolved in $10 \mathrm{~mL}$ of $0.9 \%$ $\mathrm{NaCl}$ and rat received $1 \mathrm{~mL} / \mathrm{kg} /$ day of the dissolved drug via gastric tube [12]. Group III included rats which received olanzapine (Lilly, Madrid, Spain) at dose of $0.5 \mathrm{mg} / \mathrm{kg} /$ day, according to drug calculation formula $[11,13]$. Each tablet containing $5 \mathrm{mg}$ was dissolved in $10 \mathrm{~mL}$ of $0.9 \% \mathrm{NaCl}$ and rats received $1 \mathrm{~mL} / \mathrm{kg} /$ day of the dissolved drug via gastric tube to insure that no drug loss occurred $[14,15]$.

Collection of samples. At the end of the experiment, all rats were weighed then anesthetized by intraperitoneal administration of sodium pentobarbital (Sigma-Aldrich, St. Louis, MO, USA) at a dose of $60 \mathrm{mg} / \mathrm{kg}$ bodyweight in $0.9 \% \mathrm{NaCl}$ [16]. Scrotal skin was properly shaved and disinfected with $5 \%$ iodine solution. Five $\mathrm{cm}$ incision at midline of scrotum was performed using no. 15 blade (Aesculap AG and Co. KG, Tutlingen, Germany). The right testis was taken from all rats (control and treated) and weighed. Samples were processed for both light and electron microscopic study.

Light microscopy processing. The specimens were fixed for four days in Bouin's solution and then processed through alcohol series $(70 \%, 90 \%, 100 \%)$ and embedded in wax using Leica Automated Tissue Processor Model TP1050, (Leica, Nussloch, Germany). Sections were cut from each block, $5 \mu \mathrm{m}$ in thickness. Sections were dewaxed with xylene and rehydrated through a descending alcohol series. Slides were stained with Harris hematoxylin and eosin (H \& E) [17, 18]. All sections were examined and photographed using came- 
Table 1. Adaptation of the Johnsen-like score [20] for the evaluation of spermatogenesis in rat

\begin{tabular}{|l|l|c|l|}
\hline Score & Evaluation of spermatogenesis & Score & Evaluation of spermatogenesis \\
\hline 10 & Compete spermatogenesis with mature sperm cells & 9 & Some sperm cells, with a disorganized epithelium \\
\hline 8 & Presence of few sperm cells $(<5$ to 10$)$ & 7 & No sperm cells, presence of spermatids \\
\hline 6 & No sperm cells, few spermatids $(<5$ to 10$)$ & 5 & $\begin{array}{l}\text { No sperm cells or spermatids, presence of sperma- } \\
\text { tocytes }\end{array}$ \\
\hline 4 & No sperm cells or spermatids, few spermatocytes $(<5)$ & 3 & Only spermatogonia present \\
\hline 2 & Sertoli cells only & 1 & No cells visualized in tubular cross section \\
\hline
\end{tabular}

ra and light microscope (Olympus, U-MDOB, Olympus, Tokyo, Japan) at the Research Unit, Faculty of Medicine, Taibah University, Al Medina Al Monawarrah, KSA.

Transmission Electron Microscopy processing. Small testicular specimens, $1 \mathrm{~mm}^{3}$, were fixed in $2.5 \%$ solution of glutaraldehyde in $0.1 \mathrm{M}$ cacodylate buffer $(\mathrm{pH} 7.4)$ for 2 hours and then post-fixed for 1-2 hours in osmium tetraoxide dissolved in the same buffer. Subsequently, they were dehydrated by passage through a graded ethanol series and in propylene oxide, and then embedded in epoxy resin. The embedded blocks were cut into semi-thin sections $(0.5 \mu \mathrm{m})$ with a diamond knife, stained with $1 \%$ toluidine blue, examined and photographed. Ultrathin sections (70-90 nm) were cut using an ultramicrotome. Uranyl acetate and lead citrate were used for staining of ultrathin sections [19] and studied by means of JEOL 1010 electron microscope (JEOL, Tokyo, Japan) at the Mycology and Regional Biotechnology Center, Al Azhar University, Cairo, Egypt.

Evaluation of spermatogenesis. Spermatogenesis was assessed using the Johnsen-like score. The Johnsen score [20] is the usual tool for classifying human spermatogenesis, and it was adapted to be used in the rabbit spermatogenesis analysis. The adapted Johnsen score was called the Johnsen-like score [21]. In each biopsy, 50-100 cross sections of seminiferous tubules were evaluated [22] according to criteria presented in Table 1.

Morphometric study. Leica Qwin 500 (Imaging System, Cambridge, UK) was used for measuring the area of seminiferous tubules $/ \mu \mathrm{m}^{2}$, height of spermatogenic cells (SGs), count of both Sertoli (SCs) and SGs in H \& E stained sections. Thickness of basement membrane was measured in toluidine blue stained sections $(\times 1000)$. Calculation of spermatogenic index (SI); SG count/SC count was done. Five non-overlapping sections from each paraffin block were taken and examined at low-power fields $(\times 200)$, except for SC and SG counts which were taken from high-power fields (× 400) [10]. Morphometric measurements were taken within frame area of $293.4288 \mu \mathrm{m}^{2}$. Morphometry was carried out at the Image Analysis Unit, Anatomy Department,
Faculty of Medicine, Taibah University, Al Medinah Al Monawarrah, KSA.

Statistical analysis. All data were expressed as mean \pm SEM, except for calculation of SI and Johnsen-like score where data were expressed as mean \pm SD. Statistical analyses were performed using IBM SPSS software version 19.00 (Chicago, Illinois, USA). One-way analysis of variance (ANOVA) (data were normally distributed and variances of populations were equal), post-hoc and least significant difference (LSD) were performed for inter-group comparison. $\mathrm{P}>0.05, \mathrm{P} \leq 0.05$ and $\mathrm{P} \leq 0.001$ were considered non-significant, significant and highly significant, respectively [23].

\section{Results}

\section{Assessment of testis histology by light microscopy}

\section{Hematoxylin and eosin stained sections}

The most frequent histological pattern of the testis of the control group was normal histology of seminiferous tubules (ST) with normal shape and arrangement of their cellular components (Figure 1A). Spermatogonia (Sg) and Sertoli cells (SCs) rest on intact basement membranes. Large primary spermatocytes (PS) with characteristic large rounded nuclei, round spermatids, elongated spermatids and late-stage sperms attached to the apices of SCs were seen (Johnsen-like score 10) (Figure 1A).

The microscopic examination of aripiprazoleand olanzapine-treated groups revealed a mosaic of different seminiferous tubules varying from tubules with complete, or incomplete although reduced spermatogenesis, to tubules with maturation arrested up to the level of the spermatocytes (Figure 1B, C). The ST showed numerous morphological abnormalities.

Aripiprazole-treated group showed degenerated ST with numerous normally oriented SCs, vacuolated cytoplasm of spermatogonia, small-sized primary spermatocytes with small dark nuclei and more acidophilic cytoplasm, few sperms and intact basal membranes, separation of basal and adluminal cellu- 

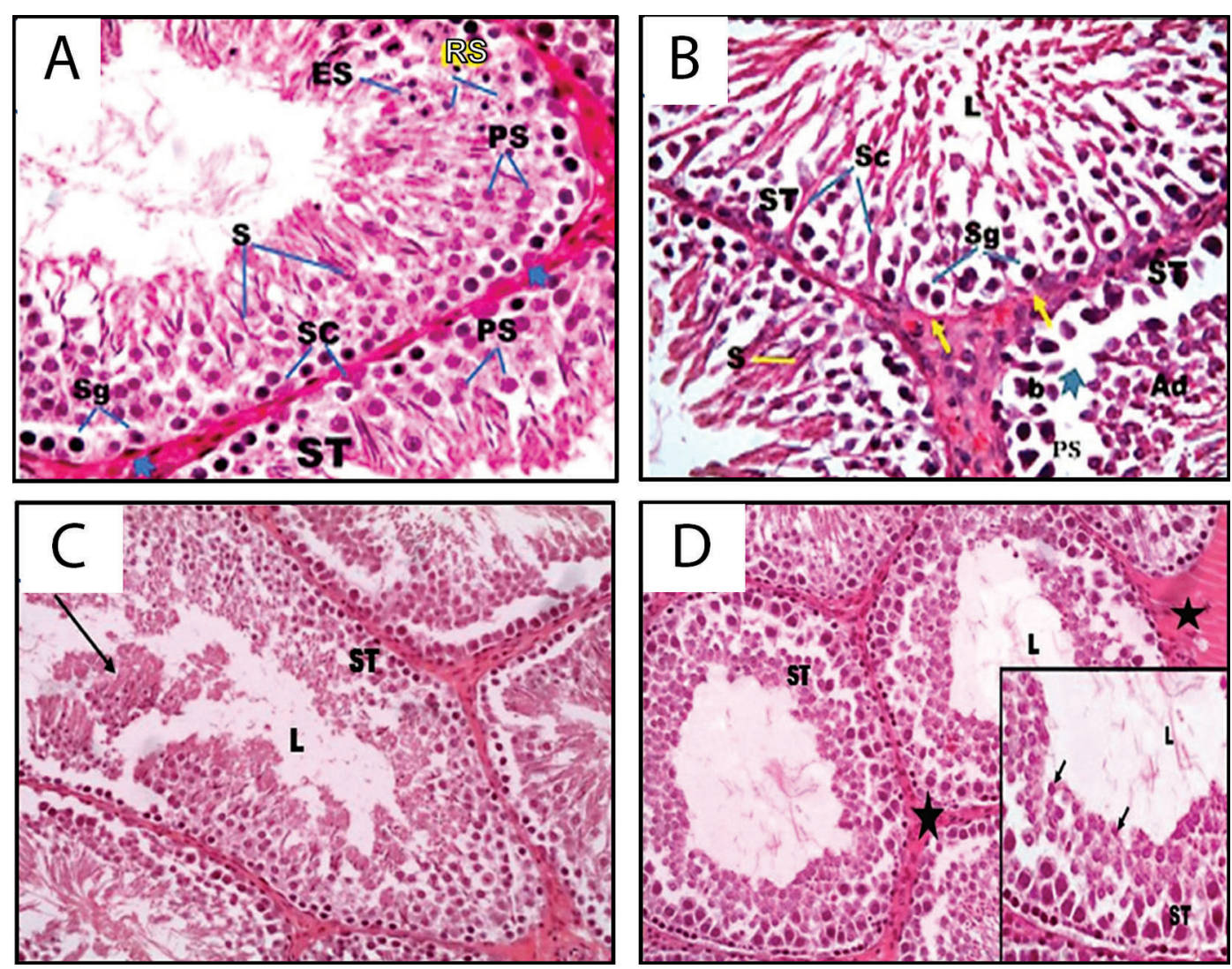

Figure 1. Histological structure of rat testis as assessed in paraffin sections. Hematoxylin and eosin staining. A. Control rat. Normal shape of seminiferous tubules (ST) with normal arrangement of spermatogonia (Sg) and Sertoli cells (SCs) resting on intact basement membrane (arrowhead). Typical structure of primary spermatocytes (Ps), round (RS) and elongated spermatids (ES) and late stage sperms (S) at the apices of SCs (Johnsen-like score 10); B. Aripiprazole treatment. Degenerated ST, with numerous normally-oriented SCs, vacuolated cytoplasm of Sg, small-sized PS with small dark nuclei and acidophilic cytoplasm, few sperms (S), intact basement membrane (BM, arrows), separation (arrowhead) of basal (b) and adluminal (Ad) cellular compartments in some ST; C. Aripiprazole treatment. ST present many exfoliated cells (arrow) with no sperms in the lumen (L) (Johnsen-like score 7); D. Olanzapine treatment. ST have no sperms in the lumen (L), increased deposits of interstitial connective tissue. Inset shows few ES (arrows) ( $<5$ to 10, Johnsen-like score 6). Abbreviations: Ad — adluminal; b — basal; BM — basement membrane; L — lumen; ES — elongated spermatids; Ps — primary spermatocytes; RS — round spermatids; S — sperm; SCs — Sertoli cells; Sg — spermatogonia; ST — seminiferous tubule(s). Magnifications: A, B $\times 400 ; C, D \times 200$; , inset $\times 1,000$

lar compartments in some ST. Many exfoliated cells with no sperms in the lumen of some ST were also seen (Johnsen-like score 7) (Figure 1B, C).

Olanzapine-treated group showed no sperms and few elongated spermatids in the lumen of $\mathrm{ST}(<5$ to 10 , Johnsen-like score 6) and an increase in the amount of interstitial connective tissue (Figure 1D).

\section{Toluidine blue stained semithin sections}

Control group showed normal shape and cellular arrangement of ST. SCs had typical triangularly-shaped nucleus and spermatogonia rested on intact basement membrane. PS were seen during different stages of meiotic division in addition to rounded and elongated spermatids and numerous mature sperms (Figure 2A).
Aripiprazole-treated rats showed vacuolation of ST epithelium, small sized PS, round spermatids with small deeply stained nuclei, abnormal shaped elongated spermatids with vacuolated cytoplasm and some multi-vesicular giant cells (Figure 2B).

Olanzapine group showed wide intercellular spaces between SCs and shrunken Sg. Large cavity separating the cellular compartments of ST was seen in addition to abnormality in the shape and arrangement of elongated spermatids with vacuolated cytoplasm, wide intercellular spaces between them and numerous multi-vesicular giant cells with large-sized nuclei. ST had thickened basement membrane and numerous SCs, while Sg and PS were small and few in numbers (Figure 2C-E). 

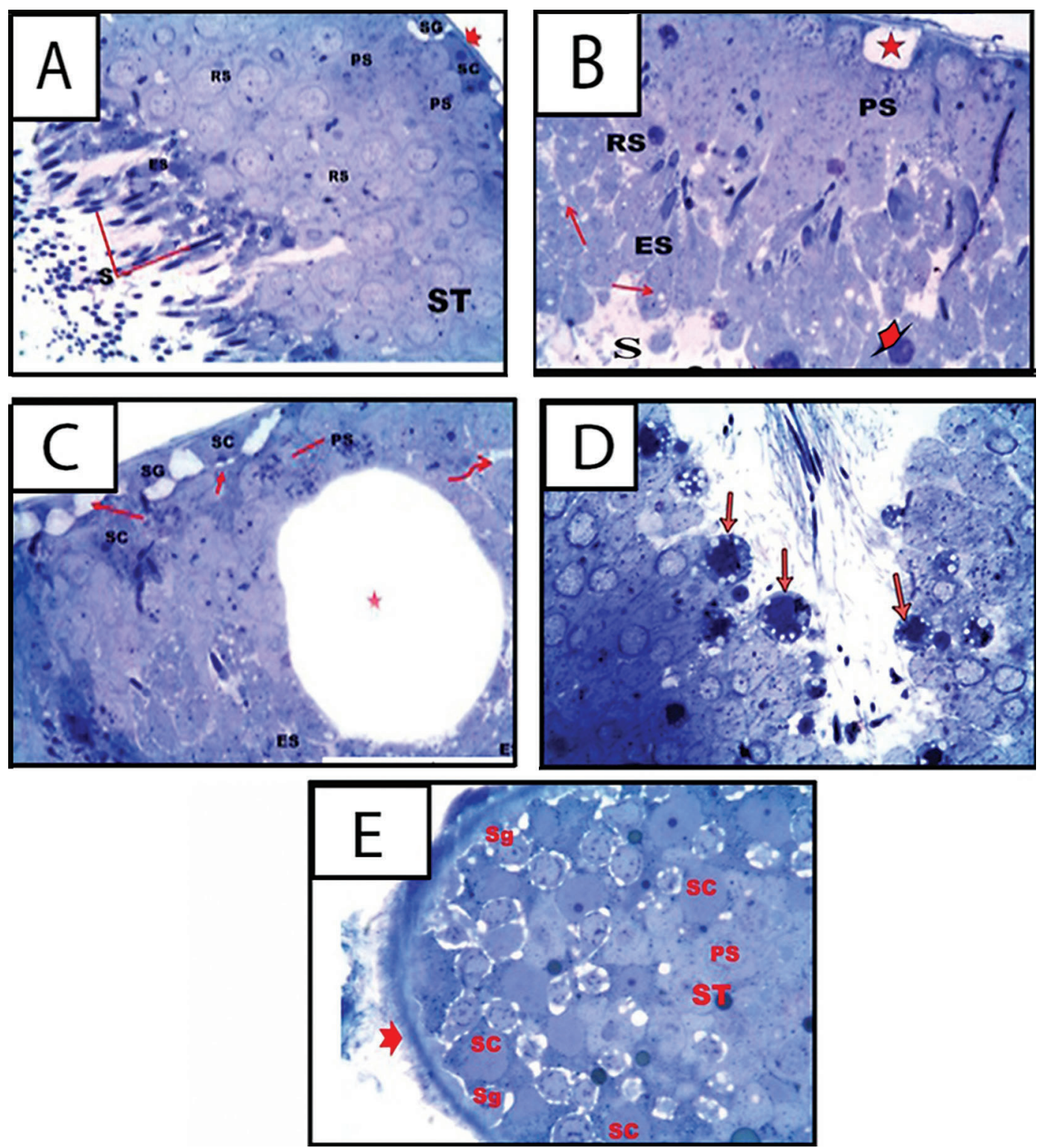

Figure 2. Histological structure of rat testis in toluidine blue stained semithin sections. A. Control rat. Seminiferous tubules (ST) have normal shape and arrangement of Sertoli cells (SCs) with triangular-shaped nuclei, spermatogonia (Sg) rest on intact basement membrane (BM, arrowhead), large primary spermatocytes (PS) in different stages of meiotic division, round (RS) and elongated (ES) spermatids and numerous mature sperms (S) are present; B. Aripiprazole treatment. ST show vacuolation (star) of the seminiferous epithelium, PS and RS with small deeply stained nuclei, abnormally shaped ES with vacuolated cytoplasm (arrows), multi-vesicular giant cells (arrowhead) and few sperms (S) in the lumen; C. Olanzapine treatment. ST show wide intercellular spaces (arrows) between SCs, shrunken spermatogenic cells (SG) and large cavity (star) between them. Small PS, abnormal shape and abnormal arrangement of ES with vacuolated cytoplasm and intercellular space (curved arrow) between spermatids are seen; D. Olanzapine treatment. ST show numerous multi-vesicular giant cells (arrows) with large sized nucleus; E. Olanzapine treatment. ST show thickened BM (arrowhead), numerous SCs, small and few spermatogenic cells (SG) and PS. Abbreviations as for Figure 1. Magnifications: A-E $\times 1,000$

\section{Evaluation of testis morphology by electron microscopy}

Control group showed ST formed of type A and B spermatogonia and Sertoli cells resting on an intact basement membrane, PS in the zygotene stage and round spermatids (Figure 3A). Round spermatids showed acrosomal vesicle spreading over their round nucleus with strict intercellular adhesion and intercellular bridges (Figure 3B). Acrosomal vesicles were seen spreading over the anterior part of the nucleus of the round spermatids where the nuclear membrane 

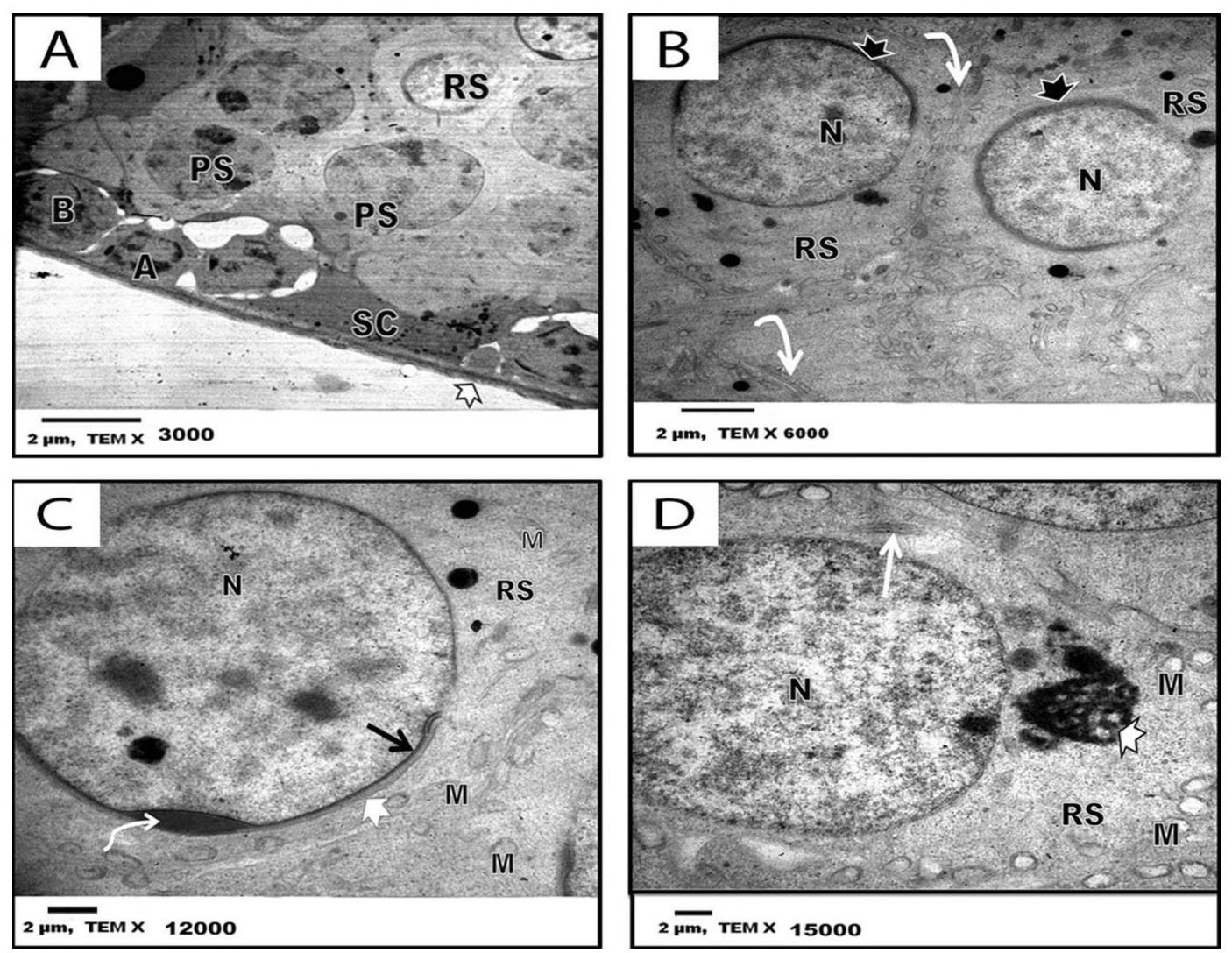

Figure 3. Ultrastructure of a seminiferous tubule of control rat. A. Spermatogonia type A (A) and type B (B) and Sertoli cells (SCs) rest on intact BM (arrowhead), round spermatids (RS) are seen. Primary spermatocytes (PS) are in the zygotene stage; B. RS have acrosomal vesicles (arrowheads) spreading over the round nucleus (N). Intercellular junctions (arrows) are visible; C. RS with acrosomal vesicle (curved arrow) which spreads over anterior part (arrowhead) of the rounded nucleus $(\mathrm{N})$ where the nuclear membrane is thickened (arrow). Mitochondria (M) can be seen; D. RS with nucleus $(\mathrm{N})$, chromatoid body (arrowhead) in the cytoplasm near the nucleus, and mitochondria (M) are located peripherally and the sectioned centriole (arrow) with manchette formation is visible. Abbreviations as for Figure 1. Magnifications: $\mathrm{A} \times 3,000 ; \mathrm{B} \times 6,000 ; \mathrm{C} \times 12,000 ; \mathrm{D} \times 15,000$

was thickened (Figure 3C). The round spermatids showed chromatoid body in their cytoplasm near the nucleus, mitochondria situated peripherally and sectioned centerioles with manchette formation. Early stages of spermatogenesis included rounded spermatids with rounded nuclei (Figure 3D).

Control group also showed that Sertoli cells had numerous lysosomes, lipid droplets and cytoplasmic vacuoles (Figure 4A). Late stages of spermatogenesis presented elongated spermatids with the arrangement of mitochondria around the manchette. Sperms showed head with elongated electron dense nuclei surrounded by acrosomal system (Figure 4B). Cross sections of mature sperm revealed normal structure of middle pieces of sperms which were formed of central axoneme surrounded by fibrous sheath, then mitochondrial sheath and covered by plasma membrane. The end piece of the tail was formed of axoneme only (Figure 4C).
In the aripiprazole-treated group, ST contained shrunken Sg and normally oriented SCs, both resting on intact thick BM. Apparently small-sized PS with rounded nuclei were seen in the zygotene stage with a synaptonemal complex. Wide intercellular spaces between Sertoli cells and spermatogonia were seen (Figure 5A). Intercellular spacing between SCs and type A and type B spermatogonia were observed. Small -sized PS with small nucleus were seen (Figure 5B). SCs contained triangularly-shaped nuclei, prominent electron dense nucleolus and abnormal large crescent-shaped mitochondria. SCs rested on intact thickened BM with prominent collagen deposition that was surrounded by myoid cells (Figure 5C). SCs also contained cytoplasmic autophagic vacuoles, dilated smooth endoplasmic reticulum and enlarged mitochondria (Figure 5D).

Moreover, in the aripiprazole-treated group wide intercellular spaces were found between primary PS 

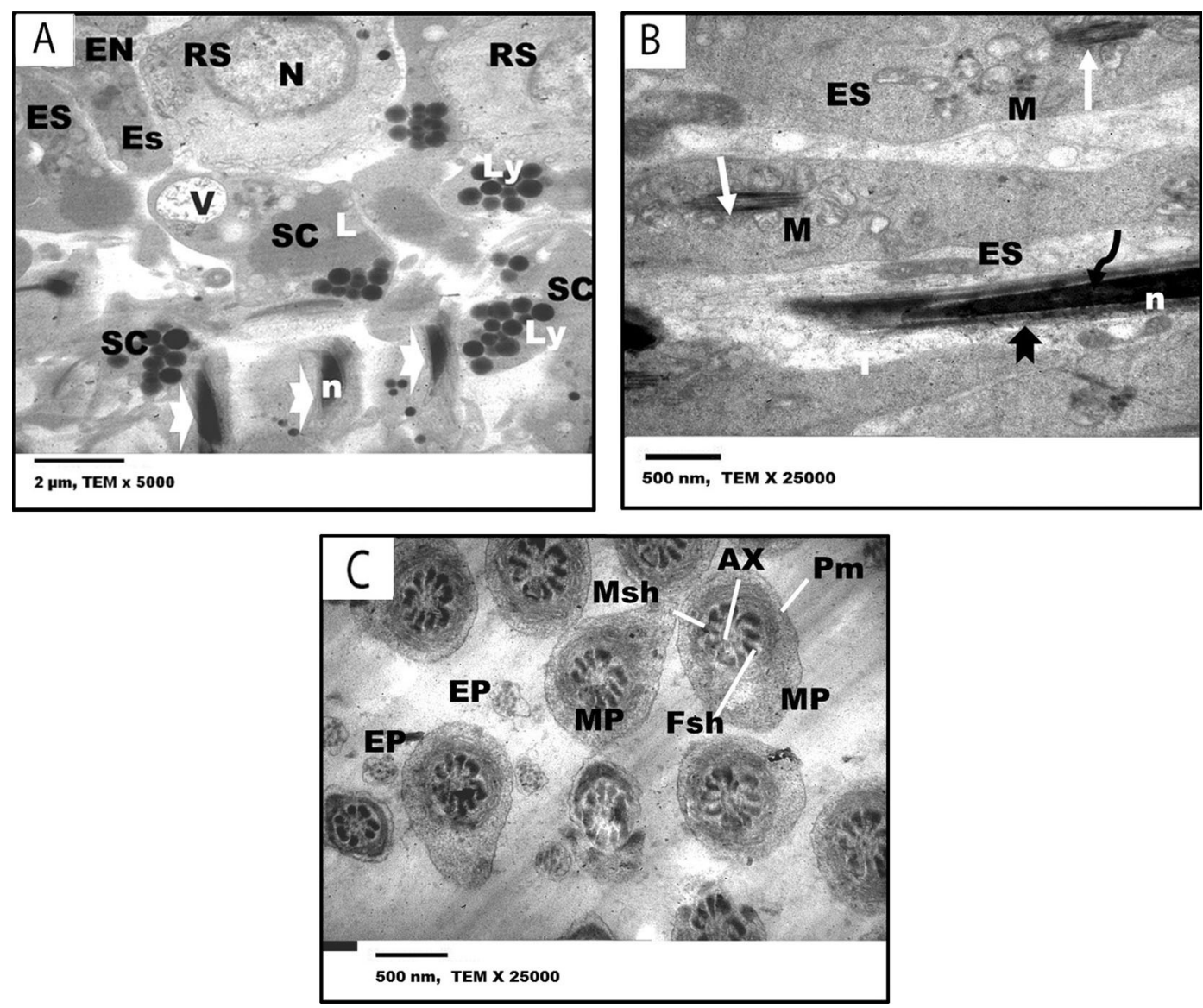

Figure 4. Ultrastructure of a seminiferous tubule of a control rat. A. Luminal part contains various stages of spermatogenesis. Round spermatids (RS) have rounded nucleus (N) while elongated spermatids (ES) contain elongated nuclei (EN). Spermatozoa (arrowheads) have elongated electron dense nuclei (n) oriented toward Sertoli cells (SCs) which contain numerous lysosomes (Ly), lipid droplets (L) and cytoplasmic vacuoles (V); B. At the late stage of spermatogenesis elongated spermatid (ES) with arrangement of mitochondria (M) around the manchette (arrows) is visible. Spermatozoa (arrowhead) show heads with elongated electron-dense nucleus (n) surrounded by acrosomal system (curved arrow); C. Middle piece (MP) of sperms has axoneme (Ax) surrounded by fibrous sheath (Fsh), mitochondrial sheath (Msh) and plasma membrane $(\mathrm{Pm})$. End pieces $(\mathrm{EP})$ are also seen. Abbreviations as for Figure 1. Magnifications: A $\times 5,000$; $\mathrm{B} \times 25,000 ; \mathrm{C} \times 25,000$

and round spermatids (Figure 6A). Luminal part of ST showed SCs with many lysosomes, lipid droplets and cytoplasmic vacuoles (Figure 6B). Some sperms had abnormal crescent-shaped nuclei, notched nuclei and irregular wavy acrosomal system. Round spermatids with rounded nucleus could be seen (Figure 6C). Three sperms shown in Figure 6D crossed at the middle pieces which were formed of mitochondrial and fibrous sheaths only with absent axonemes.

Olanzapine-treated group (Figure 7) presented ST with spermatogonia with small heterochromatic nuclei, SCs with typical nuclei, swollen mitochondria and dilated smooth endoplasmic reticulum, wide intercellular spaces, wavy thick basement membrane with increased depots of collagen fibers and myoid cells (Figure 7A). Shrunken spermatogonia with small heterochromatic nucleus and intracytoplasmic spaces could be seen. Spermatogonia were separated from Sertoli cells by large intercellular spaces. The BM of ST was wavy and discontinuous in some areas. Deposited areas of collagen fibers and myoid cell with irregular wavy cell membrane could be seen (Figure 7B). Sertoli cell had irregularly fissured nucleus, swollen mitochondria, dilated smooth endoplasmic reticulum, numerous cytoplasmic vacuoles and lipid droplets. Wide intercellular spaces contained cellular debris and nearly absent spermatogenic cells which left their normal position in Sertoli cells as large spaces were seen (Figure 7C). Primary spermatocytes had large cytoplasmic vacuole which contained multiple vesicles (Figure 7D).

Moreover, in the olanzapine-treated group, round spermatids with irregular outlines, heterochromatic 

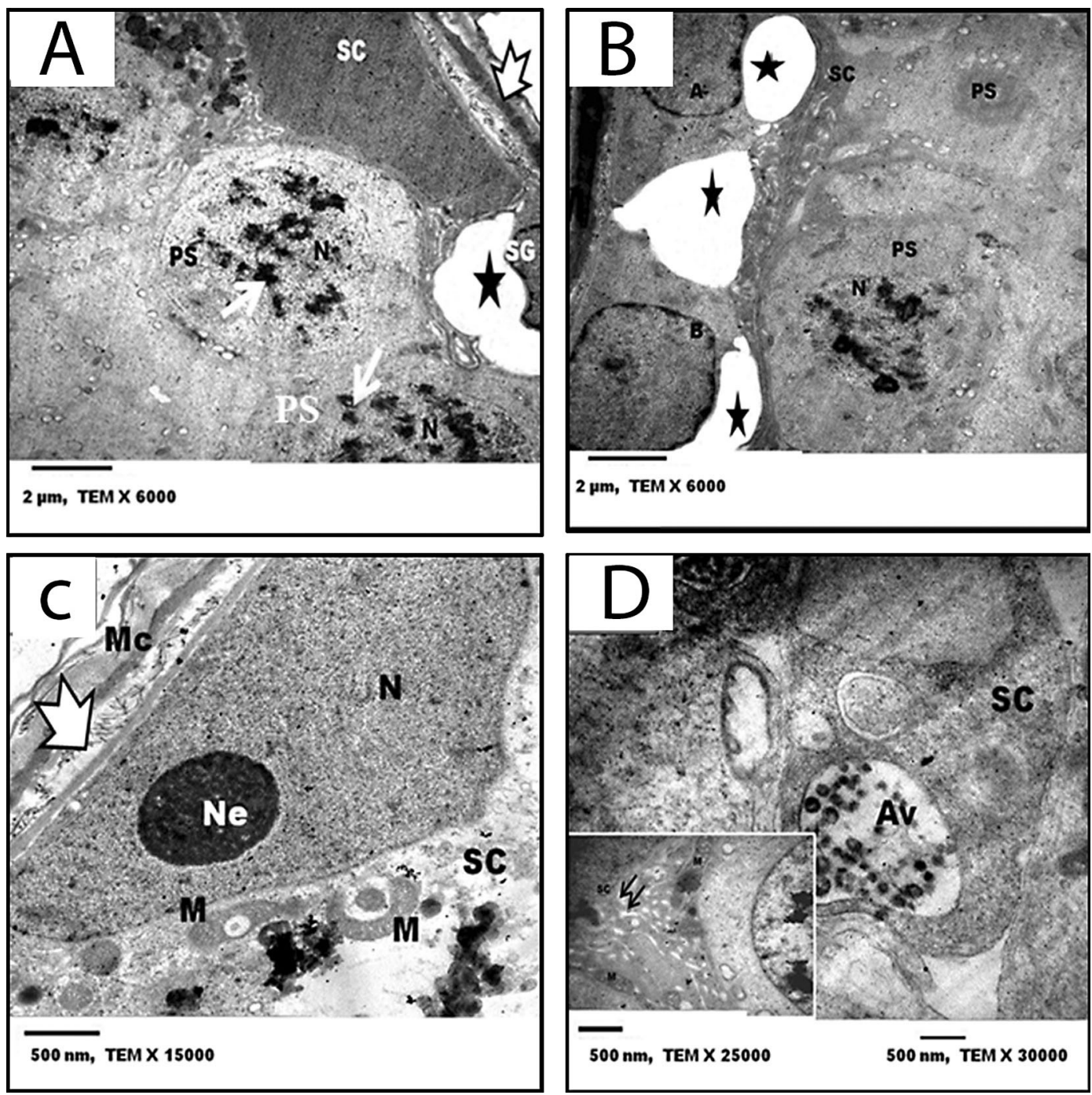

Figure 5. Ultrastructure of a seminiferous tubule in testis of aripiprazole-treated rat. A. Sertoli cells (SCs) rest on intact thick basement membrane (arrow head), primary spermatocytes (PS) with nucleus (N) in the zygotene stage with synaptonemal complexes (arrows) and wide intercellular space (star) between SCs and spermatogonia ( $\mathrm{Sg}$ ) are visible; B. Wide intercellular spaces (stars) between SCs and type A (A) and type B (B) spermatogonia and two primary spermatocytes (PS); one PS contains rounded nucleus (N) in zygotene stage while the other PS has small nucleus; C. Sertoli cells (SCs) have triangularly-shaped nucleus $(\mathrm{N})$, prominent electron-dense nucleolus $(\mathrm{Ne})$ and abnormal large crescent-shaped mitochondria (M). The intact thick basement membrane shows more collagen deposition (arrowhead) and myoid cells (Mc) than in control rat; D. Part of SCs containing cytoplasmic autophagic vacuole (Av), inset shows SCs with dilated smooth endoplasmic reticulum (arrows) and enlarged mitochondria (M). Abbreviations as for Figure 1. Magnifications: $\mathrm{A} \times 6,000$; $\mathrm{B} \times 6,000 ; \mathrm{C} \times 15,000 ; \mathrm{D} \times 30,000$; inset $\times 25,000$

nuclei, vacuolated cytoplasm and wide intercellular spaces in between were noticed (Figure 8A). Part of SCs showed abundant dilated smooth endoplasmic reticulum and intracellular spaces. The cell rested on a thick BM with increased collagen deposition. Nucleus of $\mathrm{Sg}$ could be seen (Figure 8B). Part of SCs presented with swollen mitochondria and two abnormal sperms in which both showed large rounded heads capped with swollen acrosomal system (Figure 8C).

\section{Quantitative histomorphometric studies}

Regarding the mean spermatogenic index (SI) there was highly significant decrease of SI of both aripiprazole- (reduced by $3.6 \%$ ) and olanzapine -treated rats (reduced by $25 \%$ ) in comparison to the control group. Moreover, there was significant difference of SI between the two experimental groups (Table 2). 

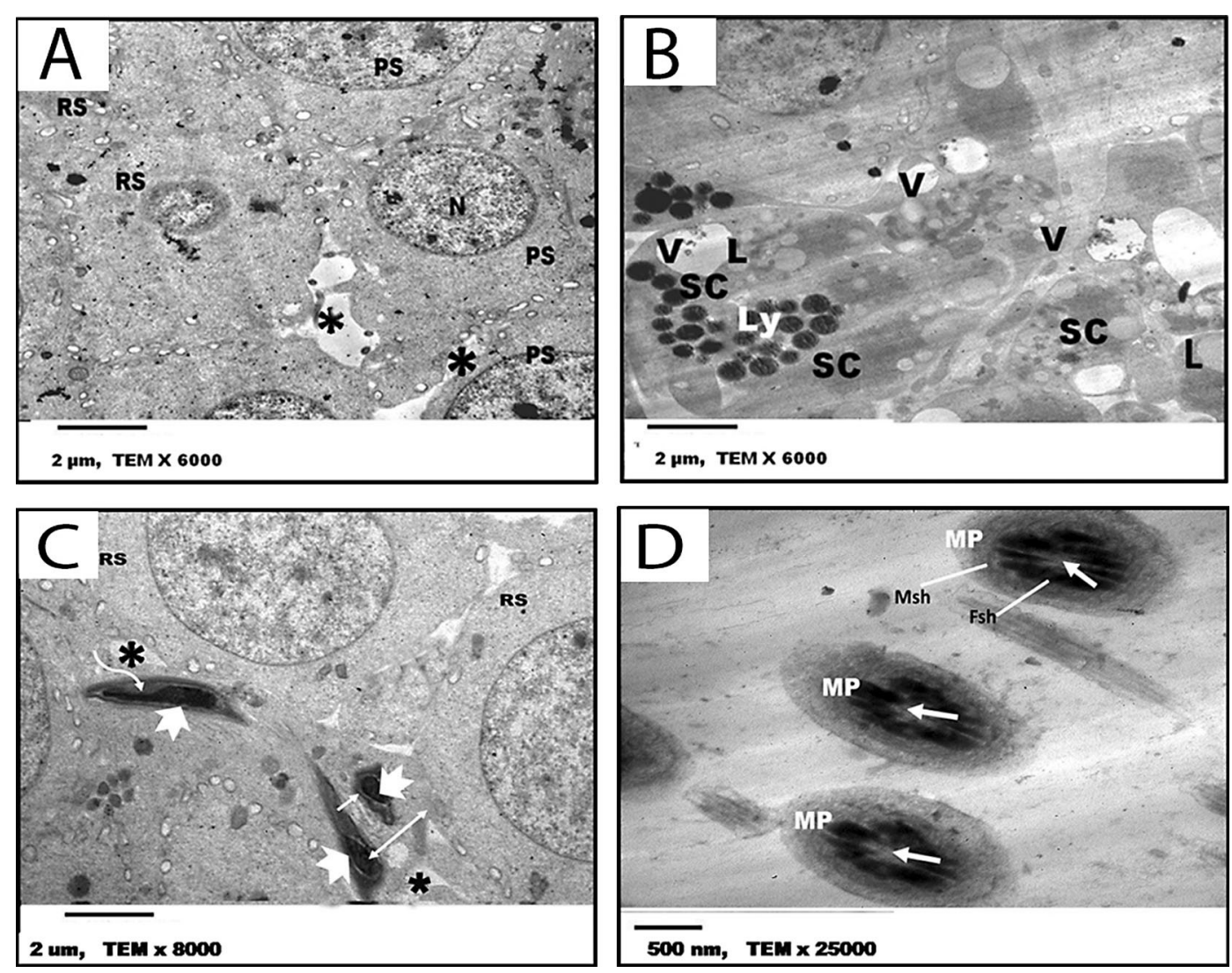

Figure 6. Ultrastructure of a seminiferous tubule in testis of aripiprazole-treated rat. A. Wide intercellular spaces (stars) between primary spermatocytes (PS) and round spermatids (RS); B. Luminal part of ST contains Sertoli cells (SCs) that have increased content of lysosomes (Ly), lipid droplets (L) and cytoplasmic vacuoles (V); C. Three sperms (arrowheads) with abnormal crescent shaped nucleus (curved arrow), notched nucleus (double-head arrow) and irregular wavy acrosomal system (short arrow) are visible. RS with rounded nucleus can be seen; D. Three sperms crossed at the middle pieces (MP) which are formed of mitochondrial sheath (Msh) and fibrous sheath (Fsh) only with absent axonemes (arrows).

Abbreviations as for Figure 1. Magnifications: A × 6,000; $\mathrm{B} \times 6,000 ; \mathrm{C} \times 8,000 ; \mathrm{D} \times 25,000$

The mean Johnsen-like scores of the experimental groups were highly significantly decreased in comparison to the control group (reduced by $19 \%$ for olanzapine and $13.6 \%$ for aripiprazole). Moreover, the mean score of olanzapine-treated rats was highly significantly lower than that of aripiprazole group (Table 2).

Although both drugs induced significant increase in rats' body weight as compared to control animals, the effect of olanzapine was much more pronounced (increase by $43.7 \%$ ) than that of aripiprazole (increase by $11.0 \%$ ). The difference between both experimental groups was statistically significant (Table 3 ). Treatment of rats with olanzapine reduced the mean weight of right testis by $29 \%$ while aripiprazole reduced it by $21.3 \%$ as compared to control animals (Table 3 ).

Mean count of Sertoli cells slightly increased in aripiprazole-treated rats (by $9.3 \%$ ) and significantly increased in olanzapine-treated animals (by $36.2 \%$ ) in comparison with the control group. Significant difference in the mean SC count between the two experimental groups was observed (Table 3 ).

Both drugs significantly reduced the mean epithelial height of seminiferous tubules as compared to control animals, aripiprazole decreased it by $38.1 \%$ whereas olanzapine decreased it by $48.7 \%$. The difference between both experimental groups was statistically significant (Table 3 ).

Compared to control animals, olanzapine decreased the number of spermatogonia by $26.1 \%$ and aripiprazole by $14.2 \%$. The difference between both experimental groups was statistically significant (Table 3).

Aripiprazole and olanzapine significantly decreased the diameter of seminiferous tubules in comparison to control group, by $40.8 \%$ and $65.6 \%$, respectively. A significant difference was also observed between the two experimental groups (Table 3). 

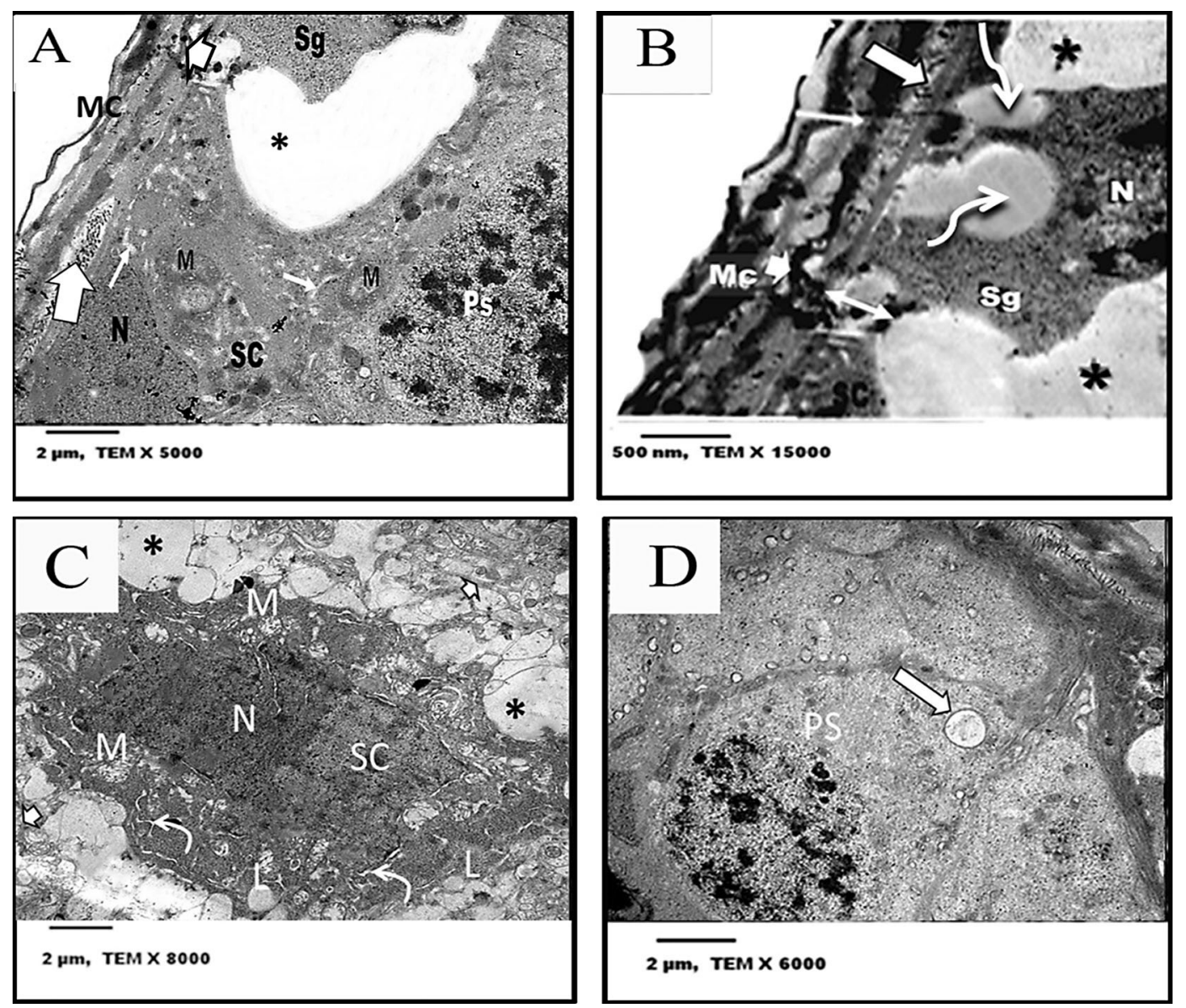

Figure 7. Ultrastructure of a seminiferous tubule in testis of olanzapine-treated rat. A. Small heterochromatic nucleus of spermatogonia $(\mathrm{Sg})$, Sertoli cells (SCs) with triangular indented nucleus (N), swollen mitochondria (M) and dilated smooth endoplasmic reticulum (arrows), wide intercellular spaces (star), wavy basement membrane (arrow head), collagen fibers (thick arrow) and myoid cells (Mc); B. Shrunken spermatogonia (Sg) with small heterochromatic nucleus $(\mathrm{N})$ and intracytoplasmic spaces (curved arrows) is widely separated from Sertoli cells (SCs) by large intercellular spaces (star). The basement membrane of ST is wavy and discontinuous in some area (arrowhead) while other area show thickening of the membrane (white arrow) with more collagen fibers (double-head arrow). Note myoid cell (Mc) with irregular wavy cell membrane; C. Sertoli cell (SC) with irregular fissured nucleus (N), has swollen mitochondria (M), dilated smooth endoplasmic reticulum (curved arrows), and lipid droplets (L). Wide intercellular spaces contain cellular debris (arrowheads). Spermatogenic cells are nearly absent leaving their sites on Sertoli cells as large spaces (stars); D. Primary spermatocyte (PS) has large cytoplasmic vacuole (arrow) contains multiple vesicles. Abbreviations: L — lipid vacuoles; $\mathrm{M}$ - mitochondria; Mc — myoid cells; N — nucleus; PS — primary spermatocytes; SC — Sertoli cell; Sg — spermatogonia. Magnifications: $\mathrm{A} \times 5,000 ; \mathrm{B} \times 15,000 ; \mathrm{C} \times 8,000 ; \mathrm{D} \times 6,000$

Both antipsychotic drugs significantly increased the mean thickness of the basement membrane of the seminiferous tubules. However, the effect of olanzapine was much more pronounced (increase by 193.5\%) than that of aripiprazole (increase by $111.8 \%$ ). A significant difference was also observed between the two experimental groups (Table 3).

\section{Discussion}

Sexual dysfunction and infertility are symptoms which are little researched in schizophrenic patients kept for long period under aripiprazole and olanzapine especially from the histopathological point of view. Therefore, this study was designed to evaluate the adverse histological effects of aripiprazole and olanzapine on the structure of seminiferous tubules of the testis in albino rats.

Testicular weight is an important parameter in the reproductive evaluation of males owing to its high and positive correlation to sperm production $[5,25]$. In this study there was high significant decrease in testicular weight of both aripiprazole and olanzapine treated groups in comparison to the control group, 

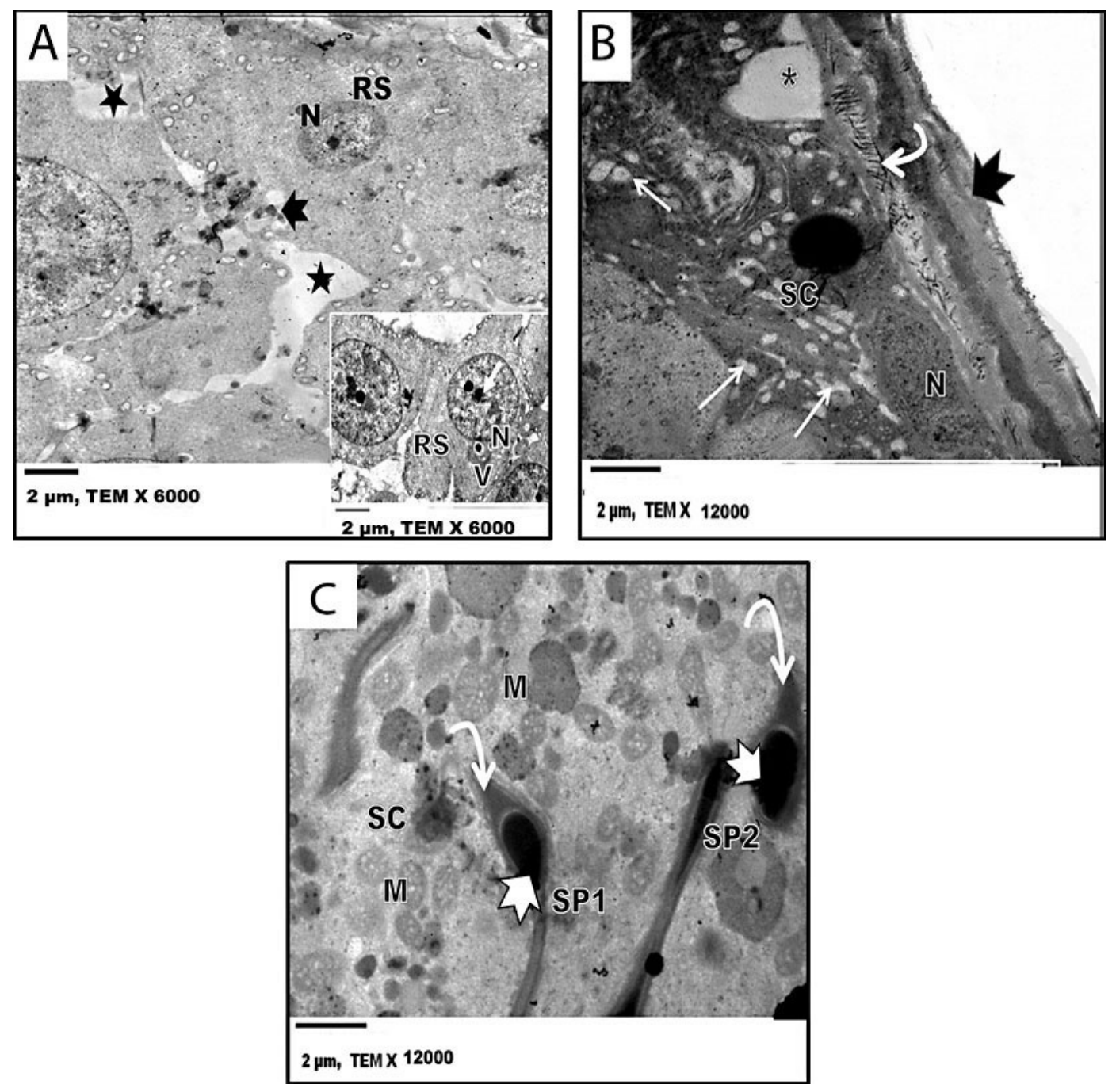

Figure 8. Ultrastructure of a seminiferous tubule in testis of olanzapine-treated rat. A. Round spermatids (RS) have irregular outlines, heterochromatic nucleus $(\mathrm{N})$, and vacuolated cytoplasm (arrowhead), wide intercellular spaces (stars) are present. Inset shows round spermatid (RS) with vacuolated cytoplasm (V) and nucleus (N) with aggregated chromatin (arrows); B. Part of Sertoli cell (SC) shows numerous dilated smooth endoplasmic reticulum (arrows) and intracellular space (star). The cell rests on a thick basement membrane (arrowhead) with prominent in collagen deposition (curved arrow). $\mathrm{N}$ - nucleus of spermatogonia; C. Part of Sertoli cell (SC) with swollen mitochondria (M) and two abnormal sperms (SP1 and SP2); both show large rounded heads (arrowheads) capped with swollen acrosomal system (curved arrows). Abbreviations: M - mitochondria; N - nucleus; V — vacuolated cytoplasm; RS — round spermatids; SC — Sertoli cell; SP1 and SP2 - sperms. Magnifications: A $\times 6,000 ; \mathrm{B} \times 2,000 ; \mathrm{C} \times 12,000$; inset $\times 6,000$

Table 2. Spermatogenic index and Johnsen-like scores of spermatogenesis in all studied groups

\begin{tabular}{|l|c|c|}
\hline Group & SI & Johnsen-like score \\
\hline Control & $7.3 \pm 0.64$ & $9.56 \pm 0.14$ \\
\hline Aripiprazole & $7.04 \pm 0.56^{*}$ & $8.26 \pm 0.38^{*}$ \\
\hline Olanzapine & $5.48 \pm 1.01^{\&, \$}$ & $7.74 \pm 0.56^{\&, \#}$ \\
\hline
\end{tabular}

Data are shown as mean $\pm \mathrm{SD} . *$ Aripiprazole $v s$. control; ${ }^{\star}$ olanzapine vs. control; ${ }^{*}$ olanzapine $v$ s. aripiprazole, all symbols refer to $\mathrm{p}<0.0001$; ${ }^{\$}$ olanzapine $v$ s. aripiprazole, $\mathrm{p}=0.029$ indicating their adverse effect on male reproductive function. Bringel et al. [10] revealed similar decrease in testicular weight of olanzapine treated rats. They attributed this to the decrease of the plasma testosterone detected in this group.

The present study showed that both olanzapine and aripiprazole produced high significant reduction in the number of spermatocytes per cross section of the ST. These results reflected by the reduced tubular diameter, seminiferous epithelium height, and SI and increased SC count. All of them indicated a reduction of spermatogenic activity 
Table 3. Rat and testis weight and morphometric evaluation of seminiferous tubules

\begin{tabular}{|c|c|c|c|}
\hline Parameter & Control & Aripiprazole-treated rats & Olanzapine-treated rats \\
\hline Body weight $[\mathrm{g}]$ & $279.45 \pm 1.3$ & $307.4 \pm 2.04^{*}$ & $401.65 \pm 10.6^{\&, \#}$ \\
\hline Weight of right testis [g] & $2.68 \pm 0.04$ & $2.11 \pm 0.07^{*}$ & $1.9 \pm 0.09^{\&}$ \\
\hline Sertoli cell count & $21.5 \pm 0.51$ & $23.5 \pm 0.38^{\mathrm{s}}$ & $29.3 \pm 0.98^{\&, \#}$ \\
\hline Spermatogonia count & $163.9 \pm 1.9$ & $140.5 \pm 1.1^{*}$ & $121.0 \pm 2.5$ \\
\hline Height of ST epithelium $[\mu \mathrm{m}]$ & $611.9 \pm 6.2$ & $378.4 \pm 5.9^{*}$ & $313.6 \pm 1.6^{\&, \#}$ \\
\hline Diameter of ST $[\mu \mathrm{m}]$ & $924,841 \pm 11,486$ & $546,700 \pm 15,220^{*}$ & $318,230.3 \pm 39,457.9^{\&, \#}$ \\
\hline Basement membrane thickness $[\mu \mathrm{m}]$ & $19.45 \pm 0.51$ & $41.2 \pm 0.82^{*}$ & $57.1 \pm 1.4^{\&, \#}$ \\
\hline
\end{tabular}

Data are shown as mean $\pm \mathrm{SD}$; ST — seminiferous tubule. *Aripiprazole $v s$. control; ${ }^{\star}$ olanzapine $v s$. control; ${ }^{*}$ olanzapine $v s$. aripiprazole, all $\mathrm{p}<0.0001$; \$aripiprazole vs. control, $\mathrm{p}=0.047$

in animals treated with both drugs. However, the adverse effect was significantly higher in rats treated with olanzapine compared with aripiprazole-treated animals. These results were further supported by assessing spermatogenesis using Johnsen-like score. It was found that there was a significant reduction of mean score of treated groups compared with the control and the effect was more prominent in olanzapine group.

According to some authors, an increased level of prolactin can result from olanzapine use $[5,6,26]$ leading to galactorrhea and sexual dysfunction [27-29]. Increased levels of prolactin can induce hypogonadism owing to inhibition of gonadotropin releasing hormone $(\mathrm{GnRH})$, follicular stimulating hormone (FSH), luteinizing hormone (LH) and testosterone, leading to a delay in spermatogenesis as well as morphological changes in the testis [30].

Others observed a reduction in plasma levels of testosterone in rats treated with olanzapine [10]. Several studies have shown the importance of testosterone and FSH to the qualitative and quantitative maintenance of spermatogenesis [31, 32]. Therefore, reduction of plasma levels of testosterone may have led to that adverse effect on spermatogenesis.

Moreover, in one study olanzapine decreased inhibin B level below normal, indicating Sertoli cell dysfunction [6]. Serum inhibin B levels are strongly positively correlated with testicular volume and sperm counts. In infertile patients, inhibin B decreases and FSH increases. In general, there is very good correlation with the degree of spermatogenetic damage and inhibin B levels [33].

On the other hand, aripiprazole lowers serum prolactin below placebo when used as a single agent and as an adjunctive treatment. It has been shown to improve antipsychotic-induced hyperprolactinemia. Aripiprazole appears to produce significant reductions in hyperprolactinemia while maintaining therapeutic efficacy for psychosis. Though this effect on hyperprolactinemia is inconsistent $[34,35]$.

However, it has been shown in rats that dopamine receptors are present in germ cells of seminiferous tubules $[36,37]$. Considering that olanzapine and aripiprazole can bind to these receptors, a direct effect of these drugs on spermatogenesis is possible. Therefore, the effects of olanzapine on spermatogenesis may have occurred by two mechanisms: a reduced level of testosterone or a direct action on germ cells. The effect of aripiprazole on spermatogenesis may be attributed to its direct action on germ cells only [37].

The present investigation showed exfoliation of spermatocytes and early spermatids into the tubular lumina, separation of spermatogonia from the BM in some tubules and increase in the intercellular spacing in the spermatogenic cells and SCs in both treated groups. Similar results were generally found due to degenerative testicular effect of different treatments [38-41]. Sloughing of germ cells was explained by others on the basis of organization of germ cells that are held in place by a close association between their plasmalemmas and specialized junctions of cell membranes of Sertoli cells. Early signs of cellular degeneration of germ cells might lead into disturbance of structure of their plasmalemmas causing their shedding into the lumina of seminiferous tubules [38, 42, 43].

The ultrastructural changes found in this study came in agree with the adverse histological effect detected by light microscopy. The current study showed ultrastructural changes of Sertoli cells in both treated groups, although they were more prominent in olanzapine-treated group. Sertoli cells had swollen mitochondria, dilated smooth endoplasmic reticulum, numerous cytoplasmic vacuoles and lipid droplets. Wide intercellular spaces contained cellular debris and nearly absent spermatogenic cells leaving their location on Sertoli cells. Some authors suggested that vacuolation of Sertoli cells is attributed to the 
degeneration of abnormal germ cells. These vacuoles correspond to dilations of the extracellular spaces resulting from the premature exfoliation of germ cells. Degenerating cells that are phagocytosed by the Sertoli cells give rise to an accumulation of lipid droplets in the cytoplasm of Sertoli cells. These ultrastructural changes are found in progressive testicular involution with advancing age in men, which may be related to hormonal changes found in old age [44]. These findings are also detected in rats treated by well-established antipsychotic, lithium carbonate [45].

Other findings of the present study were that spermatogonia had small heterochromatic nucleus in olanzapine treated group. This indicated inactive DNA of cells [46] and that the decreased thickness of germinal epithelium in our study may be partly due to decreased cell division [47].

Our results also showed apoptotic cells in the testes of olanzapine treated rats. Other changes, such as shrunken spermatogonia, separation of spermatogonial cells from each other and from basal lamina as well as mitochondrial vacuolization, could also be considered as pre-apoptotic signs. These findings are similar to that found in testicular epithelium of rats treated by cysplatin [47]. Apoptosis has a critical role on the removal of damaged spermatogonial cells to prevent the formation of abnormal sperms. It is also shown that spermatocytes that fail to complete their mitotic division are removed by apoptosis [48]. Previous studies showed induction of apoptosis in male germ cell by testosterone withdrawal [49] and after vasectomy [50]. So, the decreased thickness of germinal epithelium in our study, could be explained by the increased apoptosis due decreased testosterone.

Regarding the separations between germinal epithelial cells and between them and basement membrane as well as Sertoli cells, previous studies reported that cadherin-mediate adhesion between Sertoli cells and germ cells [51]. Cadherins control the interaction between Sertoli cells and germ cells and maintain the survival of germ cells. It has thought that cadherin-based adhesion activates intracellular signaling cascades that control cell survival, migration and maturation [52].

In the present study, the head and acrosomal caps of the spermatozoa have been adversely affected by the administration of olanzapine and aripiprazole. They possessed irregular and redundant acrosomes and irregular, notched, large heads. These effects are consistent with other findings such as in case of treatment of rats with indenopyridine-CDB-4022 [40, 41]. In monkeys following long-term vas deferens occlusion with styrene maleic anhydride, the nuclei and acrosomes of the spermatids showed different degrees of disorders [39]. Acrosomes were irregular and abnormally configured in rats treated with nicotine [53]. Ultrastructural testicular changes in mice induced by the venom of Mapanare snake included marked lesions of the acrosomes of the spermatids [54]. In case of fungicide "benomyl"-treated rats, spermatids exhibited similar degenerative changes such as abnormal development of the heads and acrosomes or lack of acrosomes [38].

Multivesicular giant cells were seen in the testes of both treated groups but were more numerous in olanzapine treated groups. It was reported that anabolic steroids caused formation of giant cells in the lumen of seminiferous tubules in rabbit. Giant cells appeared to be one of the vital signs of testicular atrophy [55]. It resulted from fusion of spermatids due to alterations in the intercellular bridges [56], failure of cytokinesis [57, 58] or an increase in the phagocytic capacity of apoptotic spermatogenic cells $[59,60]$.

The current study revealed thick, wavy and discontinuous basement membrane of seminiferous tubules as well as irregular and wavy cell membrane of myoid cell in olanzapine-treated rats. Similar findings were observed in irradiated rats [61] and in efferent ligation [62]. It was explained by either contraction of myoid cells or reduction of tubular diameter. Testosterone and several substances such as prostaglandins, oxytocin, TGF- $\beta$ have been suggested to affect the contraction of myoid cells. Changes of testosterone level or damaging of epithelium stimulates secretion of some factors such as oxytocin or prostaglandins causing myoid cells contraction [63].

Rats treated by olanzapine presented high increase in basement membrane thickness as well as deposition of collagen fibers. Basement membrane is synthesized by both Sertoli and myoid cells. Increased basement membrane thickness occurs also in aging [64], efferent ligation [62] and after irradiation [61]. This alteration either is due to increase collagen production by Sertoli or myoid cells or reduction of proteolysis rate in extracellular matrix. In efferent ligation the gene expression of laminin was changed in Sertoli cells and their protein synthesis was enhanced [62].

\section{Conclusions}

Both olanzapine and aripiprazole had adverse effects on the structure of the seminiferous tubules of rat testis as detected by light and electron microscopic changes which were confirmed by morphometric study. Nevertheless, these effects were more prominent in olanzapine-treated rats than in aripiprazole group. Further studies involving the measurements of prolactin, testosterone, FSH, LH and GnRH 
serum concentrations are strongly recommended to established potential causes of the anti-reproductive effect of olanzapine and aripiprazole.

\section{References}

1. Ambataro F, Blasi G, Leonardo F et al. Treatment with olanzapine is associated with modulation of the default mode network in patients with schizophrenia. Neuropsychopharmacology. 2010;35:904-912.

2. Guillin O, Laruelle M. Neurobiology of dopamine in schizophrenia. Cell Sci Rev. 2005; 2:1-37.

3. Epolia R, Mireille B, Ameer YT et al. Chronic valproate treatment blocks d2-like receptor-mediated brain signaling via arachidonic acid in rats. Neuropharmacology. 2011;61:1256-1264.

4. Bellack AS. Scientific and consumer models of recovery in schizophrenia: concordance, contrasts, and implications. Schizophrenia Bulletin. 2006;32:432-442.

5. Wieck A, Haddad PM. Antipsychotic-induced hyperprolactinaemia: Mechanisms, clinical features and management. Drugs. 2004;64:2291-2314.

6. Konarzewska B, Wołczyński S, Szulc A, Galińska B, Popławska R, Waszkiewicz N. Effect of risperidone and olanzapine on reproductive hormones, psychopathology and sexual functioning in male patients with schizophrenia. Psychoneuroendocrinology. 2009;34:129-139.

7. Burris KD, Molski TF, Xu C et al. Aripiprazole, a novel antipsychotic, is a high-affinity partial agonist at human dopamine D2 receptors. J Pharmacol Exp Ther. 2002;302:381-389.

8. Wahl R, Ostroff R. Reversal of symptomatic hyperprolactinemia by aripiprazole. Am J Psych. 2005;162:1542-1543.

9. Consumer Health Resource Group, LLC (2009-09-19). Abilify Side Effects. www.askapatient.com. http://www.askapatient. com/viewrating/ABILIFY.

10. de Siqueira Bringel S, Amorim Junior AA, Amorim MJ et al. Endocrine and testicular changes induced by olanzapine in adult Wistar rats. J Appl Toxicol. 2011;33:24-31.

11. Felici A, Verweij J, Sparreboom A. Dosing strategies for anticancer drugs: the good, the bad and body-surface area. Eur J Cancer. 2002;38:1677-1684.

12. Zhang Z, Zhang X, Yao Z et al. Association of antipsychotic drug-induced weight gain with a 5-HT2C receptor gene polymorphism. Lancet. 2002;82:1097-1101.

13. Shannon RS, Minakshi N, Nihal A. Dose translation from animal to human studies revisited. FASEBJ. 2007;22:660-670.

14. Mortimer PAM. Review: aripiprazole for schizophrenia more high quality research required. Evid Based Ment Health. 2007;10:14-17.

15. Silver GA, Gutierrez-Esteinou R, McQuade RD. Aripiprazole - data on efficacy and associated mortality. BrJ Psychiatry. 2007; 191:86-89.

16. Rosa ZA, Concha GA, Diana AR et al. Inhibition of liver trans-sulphuration pathway by propargylglycine mimics gene expression changes found in the mammary gland of weaned lactating rats: role of glutathione. Biochem J. 2005:373:825-834.

17. Drury R, Wallington EA. Carlton' Histological Technique, $5^{\text {th }}$ ed. Oxford University Press: New York, Toronto; 1980: 150-190.

18. Bancroft JD, Stevens A. Theory and practice of histological technique, $4^{\text {th }}$ ed. Churchill Livingston: New York, Tokyo; 1996:55-57.

19. Glauret AM, Lewis PR. Biological specimen preparation for transmission electron microscopy, $1^{\text {st }}$ ed. Portland Press: London; 1998.
20. Johnsen SG. Testicular biopsy score count — a method for registration of spermatogenesis in human testes: normal values and results in 335 hypogonadal males. Hormones. 1970;1:2-25.

21. Oliveira-Filho AB, Souza RS, Azeredo-Oliveira MTV, Peruquetti RL, Cedenho AP. Microdissection testicular sperm extraction causes spermatogenic alterations in the contralateral testis. Genet Mol Res. 2010;9:1405-1413.

22. Filipiak E, Suliborska D, Laszczynska M et al. Estrogen receptor alpha localization in the testes of men with normal spermatogenesis. Folia Histochem Cytobiol. 2012;50:340-345.

23. Dean J, Dean AJ, Coloumbier D. Epi-Info. Software computer package was on microcomputer for epidemiology, statistics and data processing. CDC, USA. 2004.

24. Soliman HM, Wagih HM, Algaidi SA, Hafiz AH. Histological evaluation of the role of atypical antipsychotic drugs in inducing non-alcoholic fatty liver disease in adult male albino rats (light and electron microscope study). Folia Biologica. 2013;59:173-180.

25. França LR, Russell LD. The testis of domestic mammals. In: Russell LD, ed. Male Reproduction: a Multidisciplinary Overview. Churchill Communictions Europe España: Madrid; 1998:198-219.

26. Kelly DL, Conley RR. Sexuality and schizophrenia: a review. Schizophrenia Bull. 2004;30:767-779.

27. Peuskens J, Pani L, Detraux J, De Hert M. The effects of novel and newly approved antipsychotics on serum prolactin levels: a comprehensive review. CNS Drugs. 2014;28:421$-453$.

28. Schlechte JA. Prolactinoma. New EnglJ Med. 2003;349:2035-2041 .

29. Chen YL, Cheng TS, Lung FW. Prolactin levels in olanzapine treatment correlate with positive symptoms of schizophrenia: results from an open-label, flexible-dose study.J Clin Psychiatry. 2009;11:16-20.

30. De Rosa M, Zarrilli S, Di Sarno A et al. Hyperprolactinemia in men. Endocrine. 2003;20:75-82.

31. França LR, Avelar GF, Almeida FFL. Spermatogenesis and sperm transit through the epididymis in mammals with emphasis on pigs. Theriogenology. 2005;63:300-318.

32. Walker WH, Cheng J. FSH and testosterone signaling in Sertoli cells. Reproduction. 2005;130: 15-28.

33. Meachem SJ, Nieschlag E, Simoni M. Inhibin B in male reproduction: pathophysiology and clinical relevance. Eur $J$ Endocrinol. 2001;145:561-571.

34. Byerly MJ, Marcus RN, Eudicone JM, Whitehead R, Baker RA. Effects of aripiprazole on prolactin levels in subjects with schizophrenia during cross-titration with risperidone or olanzapine: Analysis of a randomized, open-label study. Schizophrenia Res. 2009;107:218-222.

35. Kotorki P, Pelka P, Leotsakou C et al. Reversal of symptomatic antipsychotic-induced hyperprolactinemia with addition of aripiprazole. Ann Gen Psychiatry. 2010;9:164-170.

36. Hyun JS, Bivalacqua TJ, Baig MR et al. Localization of peripheral dopamine D1 and D2 receptors in rat coupus cavernosum. BJU Int. 2002;90:105-112.

37. Otth C, Torres M, Ramírez A et al. Novel identification of peripheral dopaminergic $\mathrm{d} 2$ receptor in male germ cells. J Cell Biochem. 2007;100:141-150.

38. Hess RA, Nakai M. Histopathology of the male reproductive system induced by the fungicide benomyl. Histol Histopathol. 2000;15:207-224.

39. Mishra PK, Manivannan B, Pathak N et al. Status of spermatogenesis and sperm parameters in langur monkeys following long-term vas occlusion with styrene maleic anhydride. J Androl. 2003; 24:501-509. 
40. Hild SA, Reel JR, Dykstra MJ, Mann PC, Marshall GR. Acute adverse effects of the indenopyridine CDB-4022 on the ultrastructure of Sertoli cells, spermatocytes and spermatids in rat testes: Comparison to the known Sertoli cell toxicant Di-n-pentylphthalate (DPP). J Androl. 2007;28:621-629.

41. Sasso Cerri E, Cerri PS. Morphological evidences indicate that the interference of cimetidine on the peritubular components is responsible for detachment and apoptosis of Sertoli cells. Reprod Biol Endocrinol. 2008;9:6-18.

42. Vogl AW, Pfeiffer DC, Redenbach DM. Ectoplasmic ("junctional") specializations in mammalian Sertoli cells: Influence on spermatogenic cells. Ann N Y Acad Sci. 1991;637:175-202.

43. Vogl AW. Spatially dynamic intercellular adhesion junction is coupled to a microtubule-based motility system: Evidence from an in vitro binding assay. Cell Motil Cytoskeleton. 1996;34:1-12.

44. Paniagua R, Nistal M, Sáez FJ, Fraile B. Ultrastructure of the aging human testis.J Electron Microsc Tech.1991;19:241-260.

45. Ali A, Katan A, Alqudsi F, Karim S. Ultrastructural changes of the testicular tissues of immature and mature mice under the effect of lithium carbonate. Bull Alex Fac Med. 2008;44:805-815.

46. Mattei MG, Luciani J. Heterochromatin, from Chromosome to Protein. Atlas Genet Cytogenet Oncol Haematol UR. http://AtlasGeneticsOncology.org/Educ/HeterochromEng. html,2003.

47. Nejad MD, Abedelahi A, Soleimani-Rad J, Mohammadi -Roshandeh A, Rashtbar M, Azami A. Degenerative effect of cisplatin on testicular germinal epithelium. Adv Pharmaceut Bull. 2012;2:173-177.

48. Print CG, Loveland KL. Germ cell suicide: New insights into apoptosis during spermatogenesis. Bioessays. 2000;22:423-430.

49. Bakalska M, Atanassova N, Koeva Y, Nikolov B, Davidoff M. Induction of male germ cell apoptosis by testosterone withdrawal after ethane dimethanesulfonate treatment in adult rats. Endocr Regul. 2004;38:103-110.

50. Al-Maghrebi M, Kehinde EO, Anim JT. Survivin down regulation is associated with vasectomy-induced spermatogenic damage and apoptosis. Med Princ Pract. 2011;449-454.

51. Newton SC, Blaschuk OW, Millette CF. N-cadherin mediates Sertoli cell-spermatogenic cell adhesion. Dev Dyn. 1993;197:1-13.

52. Honecker F, Kersemaekers AM, Molier M, Van Weeren PC, Stoop H, De Krijger RR. Involvement of E-cadherin and beta-catenin in germ cell tumours and in normal male fetal germ cell development. J Pathol. 2004;204:167-174.

53. Guven MC, Can B, Ergun A, Saran Y, Aydos K. Ultrastructural effects of cigarette smoke on rat testis. Eur Urol. 1999;36:645-649.

54. Zárraga A, Velásquez L, Strauss M, Rodríguez Acosta A. Notes about ultrastructural testicular change in mice induced by the venom of South American mapanare snake (Bothrops colombiensis Hallowell, 1845). Rev Científ. 2003;13:436-439 .

55. Khattab FK. Histological and ultrastructural studies on the testis of rat after treatment with aluminum chloride. Aust $J$ Basic Appl Sci. 2007;1:63-72.

56. Singh SK, Abe K. Light and electron microscopic observations of giant cells in the mouse testis after efferent duct ligation. Archiv Histol Jap. 1987;50:579-585.

57. Goldsworthy TL, Fransson-Steen R, Maronpot RR. Importance of and approaches to quantification of hepatocyte apoptosis. Toxicol Path. 1996;24:24-35.

58. Abdu S B. Effect of vitamins deficiencies on the histological structure of the testis of albino mice Mus musculus. Saudi J. Biol Sci. 2008;15:269-278.

59. Wang H, Xiong W, Chen Y et al. Evaluation on the phagocytosis of apoptotic spermatogenic cells by Sertoli cells in vitro through detecting lipid droplet formation by Oil Red O staining. Reproduction. 2006;132:485-792.

60. Gouda ZA, Selim AO. A possible correlation between the testicular structure and short photoperiod exposure in young albino rats: light and electron microscopic study. Egypt J Histol. 2013;36:28-38.

61. Sawada H, Esaki M. Electron microscopic observation of 137Cs-irradiated rat testis: production of basal laminae for germ cells, despite their absence.J Electron Microsc (Tokyo). 2003;52:391-407.

62. Richardson LL, Kleinman HK, Dym M. Altered basement membrane synthesis in the testis after tissue injury. J Androl. 1998;19:145-155.

63. Maekawa M, Kamimura K, Nagano T. Peritubular myoid cells in the testis: Their structure and function. Arch Histol Cytol. 1996;59:1-13.

64. Siu MK, Cheng CY. Extracellular matrix: Recent advances on its role in junction dynamics in the seminiferous epithelium during spermatogenesis. Biol Reprod. 2004;71:375-391.

Submitted: 8 May, 2013

Accepted after reviews: 19 December, 2014 Available as AoP: 23 December, 2014 